\title{
EFICIÊNCIA DE PRODUTOS VEGETAIS NO CONTROLE DA LAGARTA-DO-CARTUCHO-DO-MILHO Spodoptera frugiperda (J.E.SMITH, 1797) (LEPIDOPTERA: NOCTUIDAE)
}

\author{
Efficience of extracts of plantas in control of fall armyworm in corn Spodoptera frugiperda \\ (J.E.SMITH, 1797) (Lepidoptera: Noctuidae)
}

\author{
Marcelo Souza Silva Oliveira ${ }^{1}$, Antonia Railda Roel ${ }^{2}$, Eduardo José Arruda ${ }^{3}$, Ana Souza Marques ${ }^{4}$
}

\begin{abstract}
RESUMO
O presente trabalho teve por objetivo avaliar a eficiência de produtos vegetais no controle de Spodoptera frugiperda (J.E.Smith, 1797) na cultura do milho. Os experimentos foram instalados, nos anos de 2002 e 2004, com a pulverização dos produtos vegetais em cinco tratamentos, e quatro repetições. No ano de 2002, os produtos testados foram: Azadirachta indica A. Juss. (extrato aquoso $2 \%$ ), e óleo a 1\%; Melia azedarach L. (extrato aquoso 2\%); Quassia amara L. (extrato aquoso 2\%); óleo de nim, Azadirachta indica 1 e $2 \%$. No ano de 2004, os produtos testados foram: A. indica (extrato aquoso 5\%), e óleo a 2\%, M. azedarach (extrato aquoso 5\%), Trichilia pallida $\mathrm{Sw}$. (extrato aquoso 5\%). As avaliações, porcentagem de infestação da lagarta-do-cartucho por parcela, foram efetuadas aos três, sete e dez dias após a pulverização dos extratos. Conclui-se que extratos aquosos das plantas A. indica $2 \%$, T.pallida $5 \%$, $Q$. amara $2 \%$ e M. azedarach $2 \%$ e $5 \%$ e óleo de A. indica $1 \%$ e $2 \%$ com adição de tenso ativo não iônico, não possuem eficiência necessária como único método de controle da largarta-do-cartucho $S$. frugiperda em condições de campo. Os produtos começam a afetar o desenvolvimento da lagarta após alguns dias da ingestão das folhas pulverizadas, observado na avaliação efetuada aos sete dias após a aplicação dos extratos.
\end{abstract}

Termos para indexação: Spodoptera frugiperda, controle de pragas, inseticidas vegetais.

\section{ABSTRACT}

The objective of this work was to study the efficiency of vegetable pesticides in the control of Spodoptera frugiperda (J.E.Smith, 1797) in corn culture. The experiments were installed, in the years of 2002 and 2004, with the spraying of the vegetable products in five treatments, and four repetitions. In the year of 2002 the tested products were: Azadirachta indica A. Juss (aqueous extract 2\%), and oil at 1\%; Melia azedarach L. (aqueous extract 2\%); Quassia amara L. (aqueous extract 2\%); nim oil, Azadirachta indica 1 and $2 \%$. In the year of 2004 the tested products were: A. indica (aqueous extract 5\%), and oil at 2\%, M. azedarach (aqueous extract 5\%), Trichilia pallida Sw. (aqueous extract 5\%). The evaluations like percentage of infestation of the fall armyworm per plot, were made three, seven and ten days after the extracts application respectively. It was possible to verify that aqueous extracts of the plants A. indica $2 \%$, . T. pallida $5 \%, Q$. amara $2 \%$ and M. azedarach $2 \%$ and $5 \%$ and A. indica oil $1 \%$ and $2 \%$ with addition of non ionic active tense, don't possess necessary efficiency as the only control method of the fall armyworm $S$. frugiperda in field conditions. The products begin to affect the development of fall armyworms some days after the ingestion of the powdered leaves, observed in the seven days after the extracts application.

Index terms: Spodoptera frugiperda, pests control, botanical pesticides.

(Recebido em 4 de outubro de 2005 e aprovado em 24 de agosto de 2006)

\section{INTRODUÇÃo}

De existência milenar, o milho representa um dos principais cereais em todo mundo e cultivados em pequenas, médias e grandes propriedades. No Brasil é considerada cultura de expressão nacional, de importância social e econômica, presente de norte a sul do País.

São utilizados, durante o desenvolvimento da cultura, insumos sintéticos como pesticidas que além de aumentar os custos de produção, poluem o ambiente e deixam resíduos nos alimentos. O controle de pragas é uma das atividades de importância econômica que deve ser enquadrada para a obtenção de maiores rendimentos. A lagarta-do-cartucho Spodoptera frugiperda (J.E.Smith, 1797) (Lepidoptera: Noctuidae), comum em gramíneas em todo continente americano, é considerada a mais importante praga da cultura do milho nas condições do Brasil, causando prejuízos aos agricultores (CRUZ et al., 1983; GALLO et al., 2002).

\footnotetext{
${ }^{1}$ Bolsista PIBIC/CNPq - Universidade Católica Dom Bosco/UCDB - Bloco de Bio-Saúde - Piso superior, sala D-103 - Avenida Tamandaré, 6.000 jardim Seminário - Cx. P. 100 - 79.117-900 - Campo Grande, MS -marcelossdeoliveira@bol.com.br

2Programa de Mestrado em Biotecnologia/UCDB - Universidade Católica Dom Bosco - Bloco de Bio-Saúde - Piso superior, sala D-103 - Avenida Tamandaré, 6.000 - jardim Seminário - Cx. P. 100 - 79.117-900 - Campo Grande, MS - arroel@ucdb.br

${ }^{3}$ Programa de Mestrado em Biotecnologia/UCDB - Universidade Católica Dom Bosco - Bloco de Bio-Saúde - Piso superior, sala D-103 - Avenida Tamandaré, 6.000 - jardim Seminário - Cx. P. 100 - 79.117-900 - Campo Grande, MS - ejarruda@ucdb.br

${ }^{4}$ Bolsista PIBIC/UCDB - Curso de Biologia/UCDB - Universidade Católica Dom Bosco - Bloco de Bio-Saúde - Piso superior, sala D-103 - Avenida Tamandaré, 6.000 - jardim Seminário - Cx. P. 100 - 79.117-900 - Campo Grande, MS - f.stopassolli@uol.com.br
} 
$\mathrm{O}$ ataque sobre o milho pode ocorrer desde a fase de plântula até o pendoamento e a formação de espigas. As pequenas lagartas começam raspando o limbo foliar, provocando o sintoma de "folha raspada". Em ataques mais tardios podem ser encontrados indivíduos entre o colmo e espiga, onde perfuram a inflorescência feminina destruindo alguns grãos. As plantas danificadas por lagartas grandes podem ser facilmente identificadas devido à grande quantidade de fezes deixada no local. Nas condições brasileiras os prejuízos causados à produção por $S$. frugiperda, dependem do estágio em que a planta se encontra por ocasião de ataque, de $15 \%$ a $34 \%$ aos 30 dias e no florescimento, respectivamente (CARVALHO, 1982).

O emprego de substâncias extraídas de plantas silvestres com o poder inseticida apresenta algumas vantagens quando comparada aos sintéticos: são renováveis, facilmente degradáveis, ou seja, não contaminam o meio ambiente. $\mathrm{O}$ desenvolvimento de resistência dos insetos a estas substâncias é lento, além de não deixarem resíduos nos alimentos, são seguros aos operadores, e de baixo custo, tornando-se acessível aos pequenos produtores.

O fato de serem produtos facilmente degradáveis, após exposição aos raios solares, é também uma desvantagem, pois em termos práticos, sua ação inseticida é rapidamente reduzida em condições de campo. Em geral, as estruturas químicas destes produtos são muito grandes e complexas, difíceis de isolar e sintetizar, e quando sintetizadas, não possuem a mesma ação que o produto natural, provavelmente pela falta de algum sinergista, estabilizante ou outro componente na sua formulação (RODRÍGUEZ \& VENDRAMIM, 1995).

Várias espécies de Meliaceae se destacam entre as famílias botânicas que apresentam ingredientes ativos com atividade inseticida, proporcionando eficiência de seus extratos (VENDRAMIN, 1997). Nessa estão incluídas Azadirachta indica A. Juss. (nim) e Melia azedarach L. (cinamomo ou santa bárbara), e ainda Trichilia pallida Sw. que tem apresentado potencial como inseticida (RODRÍGUEZ \& VENDRAMIM, 1995; ROEL et al., 2000). A espécie Quassia amara L. (Simaroubaceae) conhecida popularmente por quina é também citada como eficiente no controle de gafanhotos e pulgões.

Rodríguez \& Vendramim (1996) avaliaram a bioatividade de diversas espécies de meliáceas (incluindo quatro espécies de Trichilia), em relação a $S$. frugiperda, com extratos aquosos a 5\% incorporados em dieta artificial. A maior eficiência foi obtida com os extratos de folhas e ramos de T. pallida e M. azedarach e ramos de Cabralea canjerana (Vell.) Mart. com mortalidade larval de $100 \%$.

$\mathrm{O}$ cinamomo $M$. azedarach é de origem da Índia e da Pérsia, mas, comum no Brasil há séculos apresenta potencial em reflorestamentos e na produção de madeiras com a vantagem de possuir rápido crescimento. A sua casca é utilizada medicinalmente como vomitiva e anti-helmíntica muito potente, também como tônicas e estimulantes (MARTINEZ, 2002).

O gênero Trichilia possui muitas espécies nativas do cerrado, sendo que Pott \& Pott (2003) citaram T. pallida em sua lista de espécies nativas do Mato Grosso do Sul. Ingredientes ativos de várias espécies do gênero estão sendo pesquisados como medicinais e inseticidas, além de sua madeira ser considerada resistente a cupins. A vantagem da espécie nativa é a possibilidade de serem utilizadas em reflorestamento de áreas degradadas.

No entanto o nim, A. indica, é a mais estudada e destaca-se pela sua alta eficiência no controle de insetos, ácaros, nematóides fitófagos, fungos e bactérias causando efeitos adversos (MARTINEZ, 2002).

Sendo os produtos vegetais considerados alternativas viáveis no controle de pragas, objetivou-se avaliar a viabilidade da utilização do óleo de nim, $A$. indica e extrato aquoso de folhas e ramos de Nim, M. azedarach; Q. amara e $T$. pallida em condições de campo no controle da lagarta-do-cartucho na cultura do milho.

\section{MATERIAL E METODOS}

Os experimentos foram conduzidos na Fazenda São José da UCDB - Universidade Católica Dom Bosco em Campo Grande-MS em fevereiro de 2002 e em janeiro de 2004 em lavoura de milho com 30 dias após a germinação. O plantio da cultura de milho, cultivar BR116, foi realizado de acordo com o sistema recomendado para o Estado (EMBRAPA, 1997). O solo é tipo neossolo e o clima tipo tropical úmido, caracterizado por uma estação seca bem acentuada no inverno e chuvosa no verão, sua temperatura média anual é de $23^{\circ} \mathrm{C}$, sendo que na ocasião se caracterizava por alta temperatura e precipitação. Em fevereiro de 2002 a temperatura mínima foi de 21,11 e máxima de $30,51^{\circ} \mathrm{C}$ com 196 $\mathrm{mm}^{3}$ de precipitação. Em janeiro de 2004 a mínima de 21,76 e máxima de $29,93^{\circ} \mathrm{C}$ e $354,5 \mathrm{~mm}^{3}$ de precipitação.

Os produtos a serem testados foram obtidos de ramos e folhas das árvores de triquilia (T. pallida), do cinamomo (M. azedarach) e do nim (A. indica), com idade aproximada de três anos em fase de florescimento, na Estação Experimental do IDATERRA em Campo Grande. Galhos e ramos da espécie vegetal da quina $Q$. amara foram 
coletados de árvore adulta, no campus da UCDB. O material vegetal foi seco em estufa de esterilização e secagem por três dias a $40^{\circ} \mathrm{C}$, e moídos em moinhos de facas até obter um pó fino e após, acondicionados em frascos de vidros escuros e mantidos em lugar seco, escuro até o dia anterior da instalação dos experimentos. O óleo de nim foi importado da Índia.

$\mathrm{O}$ experimento foi conduzido em delineamento experimental de blocos ao acaso com quatro repetições por tratamento com cinco tratamentos, incluindo a testemunha. Cada parcela foi constituída por seis linhas de milho de $5 \mathrm{~m}$ de comprimento e $1 \mathrm{~m}$ entre linhas, apresentando em média cinco plantas por metro linear. As avaliações foram realizadas na área útil, que foi constituída das quatro linhas centrais, desprezando-se $1 \mathrm{~m}$ nas extremidades das linhas, perfazendo total de $16 \mathrm{~m}^{2}$. A presença do inseto vivo foi determinada pela presença de fezes no cartucho e de folhas furadas.

Os produtos vegetais frescos foram pesados e deixados de repouso em água, por cerca de 20 horas, e quando coados se obteve calda na concentração de $10 \%$ com $100 \mathrm{~mL}$ de tenso ativo não iônico (nonilfenol etoxilado com 9,5 moles de óxido de eteno), como espalhante adesivo. No campo, as caldas de $10 \%$ foram diluídas para 2 e $5 \%$ extrato aquoso $(60 \mathrm{~mL}$ do produto e $480 \mathrm{~mL}$ de água), sendo que o óleo de nim foi diluído a 1 e $2 \%(60 \mathrm{~mL}$ do produto e $540 \mathrm{~mL}$ de água). As pulverizações dos produtos testados foram de $600 \mathrm{~mL}$ por parcela (calda de $200 \mathrm{~L} / \mathrm{ha}$ ) com pulverizador costal manual com bico leque. A aplicação foi realizada após as 17:00 h, quando a luminosidade estava diminuindo.

Os produtos foram aplicados ao entardecer, com o objetivo não só de evitar deriva dos produtos como de resguardá-lo dos raios solares. Como são conhecidos, estes e outros produtos naturais, possuem limitada persistência no ambiente, sendo que a temperatura, umidade, luz ultravioleta, $\mathrm{pH}$, parte da planta tratada, chuva e outros exercem mais ou menos efeito negativo nas suas atividades (SCHMUTTERER, 1992).

Os tratamentos em fevereiro de 2002 foram: $A$. indica (extrato aquoso $2 \%$ ), e óleo a $1 \%, M$. azedarach (extrato aquoso $2 \%$ ), Q. amara (extrato aquoso $2 \%$ ), e testemunha (somente água). Os tratamentos em janeiro de 2004 foram: A. indica (extrato aquoso 5\%), e óleo a 2\%, M. azedarach (extrato aquoso 5\%), T. pallida (extrato aquoso 5\%), e testemunha (somente água). Após aplicações dos produtos, foram efetuadas avaliações aos três, sete, e dez dias, com a contagem de plantas infestadas por parcela em toda área útil.
Os dados obtidos, contagem de plantas infestadas na área útil, foram transformados em porcentagem de infestação, média das quatro repetições. Essas porcentagens foram comparadas às infestações obtidas na testemunha. A eficiência foi calculada pela fórmula de Ábbott (NAKANO et al., 1981). Em que, porcentagem de eficiência \% $\mathrm{E}=(\mathrm{T}-\mathrm{I}) /$ $\mathrm{T} \times 100$. Em que, $\mathrm{T}=$ número de insetos vivos na testemunha; $\mathrm{I}=$ número de insetos vivos no tratamento.

Utilizou-se o programa estatístico SANEST (Versão 3.0) (ZONTA \& MACHADO, 1991). As médias amostradas por tratamento em blocos ao acaso, foram comparadas pelo teste de Duncan.

As dosagens testadas foram determinadas em função dos dados de experimentos em laboratório e de testes anteriores em campo com os mesmos tratamentos.

Para o experimento 2, as dosagens foram aumentadas em função da pequena eficiência obtida no experimento 1 . O tratamento com extrato aquoso de quina ( $Q$. amara) substituiu o tratamento de T. pallida como anteriormente programado, por falta de material vegetal na ocasião.

\section{RESULTADOS E DISCUSSÃO}

\section{$1^{\circ}$ Experimento - fevereiro de 2002}

Nas avaliações efetuadas nas parcelas testemunha (pulverizadas somente com água), observou-se decréscimo da infestação natural da lagarta-do-cartucho durante o período de execução do experimento, com média de 92,3\%, $91,71 \%$ e 78,0\% de plantas com lagartas vivas nas leituras aos três, sete e dez dias, respectivamente (Tabela 1).

Na primeira avaliação, três dias após aplicação dos produtos, não foram observadas diferenças significativas entre as porcentagens de plantas atacadas, variando de 66,5 a $80,9 \%$, demonstrando, estarem todos os tratamentos iguais entre si e em relação à testemunha (Tabela 1). No entanto, os tratamentos com A. indica, extrato aquoso ou óleo, causaram redução de população de 29,0 e 28,2\%, respectivamente, em relação à testemunha.

Produtos inseticidas de origem vegetal possuem efeito após a ingestão, inibindo algumas das funções vitais, tais como reprodução, alimentação, crescimento, sempre na dependência da concentração utilizada antes de provocar mortalidade (RODRÍGUEZ \& VENDRAMIM, 1997; ROEL \& VENDRAMIM, 1999).

Na segunda avaliação, sete dias após aplicação dos produtos vegetais, foi observada menor infestação $(64,7 \%)$, nas médias das parcelas com extrato aquoso de $A$. indica em relação à testemunha $(91,7 \%)$ e significativamente diferentes. Os demais tratamentos, óleo de $A$. indica, extrato 
aquoso de $M$. azadarach e de $Q$. amara se comportaram de maneira semelhantes, mas com valores intermediários, de $73,2 \%, 76,0 \%$ e 77,9\% de infestação em relação à testemunha e o extrato aquoso de $A$. indica. No entanto, a eficiência considerada em geral baixa, variou entre 15 a 29,4\% (Tabela 1).

Dez dias após o início do experimento, não se observou diferenças significativas entre as infestações de S. frugiperda entre todos os tratamentos. Entretanto, mesmo nas parcelas tratadas com A. indica na forma de óleo foram observadas reduções na população. Os tratamentos com extrato aquoso de folhas de $A$. indica provocou o maior valor de eficiência $(29,4 \%)$, considerado baixo como medida de controle. O óleo de $A$. indica é retirado de sementes, onde os princípios ativos são mais concentrados e seus derivados mais efetivos. De acordo com Balandrin et al. (1988), dentre os componentes com atividade inseticida presentes em $A$. indica, $75 \%$ deles estão concentrados nas sementes.

Os derivados do 'nim' não matam diretamente, mas por pressão fisiológica e por inanição dos insetos, alterando invariavelmente a reprodução dos mesmos (SAXENA, 1989). Foi verificado, que em todas as leituras, os derivados de $A$. indica, óleo ou extrato aquoso, obtiveram desempenho numericamente superiores que os demais tratamentos e por período maior.

\section{Experimento 2 - janeiro de 2004}

De modo semelhante ao experimento anterior, dois dias após a aplicação dos produtos não se observou diferenças significativas quanto à infestação de $S$. frugiperda entre os tratamentos em relação à testemunha (Tabela 2).

Sete dias após a pulverização, já se notava a ação dos produtos na mortalidade larval, sendo que os produtos na forma de óleo e extrato aquoso $A$. indica e extrato aquoso de T. pallida diferiram da testemunha, com eficiência variando entre 29,55 e 36,9\% e M. azedarach com valores intermediários.

A mesma situação verificou-se dez dias após a aplicação evidenciando que tanto o óleo $2 \%$ como extrato aquoso de folhas e ramos de A. indica e de T. pallida a 5\% causou mortalidade que variou entre 35,99 e 42,87\% em comparação à testemunha. Rodríguez \& Vendramim (1995, 1996) também encontraram efeitos semelhantes com produtos à base de $A$. indica e da $T$. pallida sobre $S$. frugiperda em condições de laboratório.

Outros efeitos da ação do A. indica e de T. pallida foram observados em condições de laboratório, como perda do peso de lagartas e pupas e aumento da longevidade das fases, não afetam diretamente a população, mas ocorrem como ação deletéria dos produtos vegetais sobre as populações (BOGORNI \& VENDRAMIM, 2003; RODRÍGUEZ \& VENDRAMIM, 1996, 1997; ROEL \& VENDRAMIM, 1999; TORRECILLAS \& VENDRAMIM, 2001).

A redução do peso da lagarta-do-cartucho em decorrência da alimentação com folhas de milho tratadas com extratos de T. pallida também foi relatada por Bogorni \& Vendramim (2003), Rodríguez \& Vendramim (1996, 1997), Roel \& Vendramim (1999) e Torrecillas \& Vendramim (2001).

TABELA 1 - Porcentagem de infestação de plantas de milho, com a lagarta-do-cartucho, Spodoptera frugiperda após aplicação de produtos vegetais e porcentagem de eficiência de controle nas leituras efetuadas após aplicação dos produtos. Campo Grande, 2002.

\begin{tabular}{|c|c|c|c|c|c|c|}
\hline \multirow{2}{*}{ Tratamento } & \multicolumn{2}{|c|}{$3 \mathbf{D A A}^{1}$} & \multicolumn{2}{|c|}{7 DAA } & \multicolumn{2}{|c|}{10 DAA } \\
\hline & $\% I^{2}$ & $\% \mathbf{E}^{3}$ & $\% \mathrm{I}$ & $\% \mathbf{E}$ & $\% I$ & $\% \mathbf{E}$ \\
\hline A. indica $2 \%$ & $65,5 \pm 20,2^{4} \mathrm{a}$ & 29,0 & $64,7 \pm 18,5 \mathrm{a}$ & 29,4 & $68,5 \pm 16,2 \mathrm{a}$ & 12,2 \\
\hline M. azedarach $2 \%$ & $80,9 \pm 20,0$ a & 12,4 & $76,0 \pm 14,3 \mathrm{ab}$ & 17,1 & $72,8 \pm 15,9$ a & 6,7 \\
\hline Q. amara $2 \%$ & $72,0 \pm 13,3 \mathrm{a}$ & 22,0 & $77,9 \pm 11,3 \mathrm{ab}$ & 15,0 & $75,8 \pm 21,5 \mathrm{a}$ & 2,8 \\
\hline A. indica $1 \%$ - óleo & $66,3 \pm 23,4 \mathrm{a}$ & 28,2 & $73,2 \pm 11,7 \mathrm{ab}$ & 20,4 & $67,0 \pm 9,0 \mathrm{a}$ & 14,1 \\
\hline Testemunha & $92,3 \pm 6,0 \mathrm{a}$ & --- & $91,7 \pm 5,2 \mathrm{~b}$ & --- & $78,0 \pm 15,4 \mathrm{a}$ & --- \\
\hline $\mathrm{CV}$ & $22,47 \%$ & & $16,78 \%$ & & $23,73 \%$ & \\
\hline
\end{tabular}

1 daa $=$ Dias após a aplicação

$2 \% \mathrm{I}=$ Porcentagem de infestação

$3 \% \mathrm{E}=$ Porcentagem de eficiência calculada pela fórmula de Ábbott

${ }^{4}$ Médias seguidas da mesma letra não diferem entre si pelo teste de Duncan a 5\% de significância. 
TABELA 2 - Porcentagem de infestação de plantas de milho, com a lagarta-do-cartucho, Spodoptera frugiperda após aplicação de produtos vegetais e porcentagem de eficiência de controle nas leituras efetuadas após aplicação dos produtos. Campo Grande, 2004.

\begin{tabular}{|c|c|c|c|c|c|c|}
\hline \multirow{2}{*}{ Tratamento } & \multicolumn{2}{|c|}{$3 \mathbf{D A A}^{1}$} & \multicolumn{2}{|c|}{7 DAA } & \multicolumn{2}{|c|}{10 DAA } \\
\hline & $\% \mathbf{I}^{2}$ & $\% \mathbf{E}^{3}$ & $\%$ I & $\% \mathbf{E}$ & $\% I$ & $\% \mathbf{E}$ \\
\hline A. indica $2 \%$ - óleo & $43,59 \pm 3,9 \mathrm{a}^{*}$ & 31,10 & $52,27 \pm 18,3 \mathrm{~b}$ & 36,90 & $48,35 \pm 9,2 \mathrm{~b}$ & 42,87 \\
\hline Q. amara $5 \%$ & $44,96 \pm 14,3 \mathrm{a}$ & 28,94 & $73,85 \pm 4,9 a b$ & 10,85 & $62,85 \pm 9,4 \mathrm{ab}$ & 25,74 \\
\hline A. indica $5 \%$ & $54,29 \pm 15,4 \mathrm{a}$ & 14,19 & $58,36 \pm 4,5 \mathrm{~b}$ & 29,55 & $48,76 \pm 9,4 \mathrm{~b}$ & 42,38 \\
\hline T. pallida $5 \%$ & $38,25 \pm 15,4 \mathrm{a}$ & 39,54 & $53,87 \pm 8,1 \mathrm{~b}$ & 34,97 & $54,17 \pm 16,2 b$ & 35,99 \\
\hline Testemunha & $63,27 \pm 26,2 \mathrm{a}$ & -- & $82,84 \pm 9,3 \mathrm{a}$ & -- & $84,63 \pm 5,4 \mathrm{a}$ & -- \\
\hline $\mathrm{CV}$ & \multicolumn{2}{|c|}{$34,024 \%$} & \multicolumn{2}{|c|}{$16,140 \%$} & \multicolumn{2}{|c|}{$17,703 \%$} \\
\hline
\end{tabular}

1 daa $=$ Dias após a aplicação

$2 \% \mathrm{I}=$ Porcentagem de infestação

$3 \% \mathrm{E}=$ Porcentagem de eficiência calculada pela fórmula de Ábbott

${ }^{4}$ Médias seguidas da mesma letra não diferem entre si pelo teste de Duncan a 5\% de significância.

Hellpap (1984), utilizando dieta contendo extrato metanólico de sementes de $A$. indica em concentrações de 0,5 a $100 \mathrm{ppm}$, em lagartas de $S$. frugiperda com quatro e dez dias de idade, verificou que os tempos letais, TL50 e TL100, foram, respectivamente, 15 e 33 dias para lagartas de quatro dias de idade e 20 e 26 dias para lagartas de dez dias de idade.

A baixa eficiência dos produtos vegetais testados pode ser devido à localização da lagarta na planta, que alojada dentro do cartucho, fica protegida dos extratos pulverizados. A redução da infestação observada, em especial, após sete dias das aplicações, podem se tornar significativas se somadas ao longo do tempo, após algumas pulverizações. No entanto, são necessárias outras pesquisas para testar novas metodologias, formulações e formas de aplicação.

\section{CONCLUSÕES}

De acordo com os dados obtidos, nas condições em que o experimento foi realizado, os extratos aquosos das plantas Azadirachta indica $2 \%$, Trichilia pallida $5 \%$, Quassia amara $2 \%$ e Melia azedarach $2 \%$ e $5 \%$ e óleo de $A$. indica $1 \%$ e $2 \%$ com adição de tenso ativo não iônico, não possuem eficiência necessária como único método de controle da largarta-do-cartucho em condições de campo.

Os produtos vegetais testados começam a afetar o desenvolvimento da lagarta-do-cartucho alguns dias após a pulverização das folhas, em geral sete dias após da aplicação dos extratos.
Óleo ou extrato aquoso de $A$. indica tem efeito mais acentuado na diminuição da população da lagarta-docartucho em relação aos extratos aquosos de $M$. azedarach, Q. amara e T. pallida.

\section{REFERÊNCIA BIBLIOGRÁFICA}

BALANDRIN, M. F.; MARK-LEE, S.; KLOCKE, J. A. Biologically active volatile organosulfur compounds from seeds of the neem tree, Azadirachta indica (Meliaceae). Journal of Agricultural and Food Chemistry, [S.1.], v. 36, n. 5, p. 1048-1054, 1988.

BOGORNI, P. C.; VENDRAMIM, J. D. Bioatividade de extratos aquosos de Trichilia spp. sobre Spodoptera frugiperda (J.E. Smith) (Lepidoptera: Noctuidae) em milho. Neotropical Entomology, Londrina, v. 32, p. 665-669, 2003.

CARVALHO, A. O. R. Pragas e seu controle. In: IAPAR. O milho no Paraná. Londrina, 1982. p. 141-148. (Circular, 29).

CRUZ, I.; WAQUIL, J. M.; SANTOS, J. P.; VIANA, P. A.; SALGADO, L. O. Pragas da cultura do milho em condições de campo: métodos de controle e manuseio de defensivos. Sete Lagoas: Embrapa-CNPMS, 1983. (Circular técnica, 10).

EMPRESA BRASILEIRA DE PESQUISA BRASILEIRA. Centro de Pesquisa Agropecuária do Oeste (Dourados, MS). Milho: informações técnicas. Dourados, 1997. 222 p. (Embrapa-CPAO. Circular técnica, 5). 
HELLPAP, C. Effects of neem kernel extracts on the fall armyworm Spodoptera frugiperda. In: INTERNATIONAL NEEM CONFERENCE, 2., 1983, Rauischholzhausen. Proceedings... Eschborn: GTZ, 1984. p. 353-363.

GALLO, D.; NAKANO, O.; SILVEIRA NETO, S.; CARVALHO, R. P. L.; BATISTA, G. C. de; BERTI FILHO, E.; PARRA, J. R. P.; ZUCCHI, R. A.; ALVES, S. B. Entomologia Agrícola. Piracicaba: FEALQ, 2002. 919 p.

MARTINEZ, S. O nim Azadirachta indica: natureza, usos múltiplos, produção. Londrina: IAPAR, 2002.

NAKANO, O.; SILVEIRA NETO, S.; ZUCCHI, R. A. Entomologia econômica. Piracicaba: Livroceres, 1981.

POTT, A.; POTT, V. J. Espécies de fragmentos florestais em Mato Grosso do Sul. In: COSTA, R. B. da (Org.). Fragmentação florestal e alternativas de desenvolvimento rural na região Centro-Oeste. Campo Grande: UCDB/ Conservation, 2003.

RODRÍGUEZ, H. C.; VENDRAMIM, J. D. Toxicidad de extractos acuosos de meliáceas en larvas de Spodoptera frugiperda (J.E. Smith, 1797). Avances en La Investigacion, [S.1.], v. 1, p. 61-63, 1995.

RODRÍGUEZ, H. C.; VENDRAMIN, J. D. Toxicidad de extractos acuosos de Meliaceae en Spodoptera frugiperda (Lepidoptera: Noctuidae). Manejo Integrado de Plagas, [S.1.], n. 42, p. 14-22, 1996.

RODRÍGUEZ, H. C.; VENDRAMIM, J. D. Avaliação da bioatividade de extratos aquosos de Meliaceae sobre
Spodoptera frugiperda (J.E. Smith). Revista da Agricultura, Piracicaba, v. 72, p. 305-318, 1997.

ROEL, A. R.; VENDRAMIM, J. D. Desenvolvimento de Spodoptera frugiperda (J.E. Smith) em genótipos de milho tratados com extrato acetato de etila de Trichilia pallida (Swartz). Scientia Agricola, Piracicaba, v. 56, p. 581-586, 1999.

ROEL, A. R.; VENDRAMIM, J. D.; FRIGHETTO, R. M.; FRIGHETTO, N. Atividade tóxica de extratos orgânicos de Trichilia pallida (Swartz) (Meliaceae) sobre Spodoptera frugiperda (J.E. Smith). Anais da Sociedade Entomológica do Brasil, Londrina, v. 29, p. 799-808, 2000.

SAXENA, R. C. Inseticides from Neem. In: ARNASON, J. T.; PHILOGENE, B. J. R.; MORAND, P. (Eds.). Inseticides of plant origin. Washington: ACS, 1989. cap. 9, p. 110-129.

SCHUMUTTERER, H. Higher plants as souces of novel pesticides. In: Insecticides: mecanism of action and resistence. Andover: Intercept, 1992. p. 3-15.

TORRECILLAS, S. M.; VENDRAMIM, J. D. Extratos aquosos de ramos de Trichilia pallida e o desenvolvimento de Spodoptera frugiperda em genótipos de milho. Scientia Agricola, Piracicaba, v. 58, p. 27-31, 2001.

VENDRAMIN, J. D. Uso de plantas inseticidas no controle de pragas. In: CICLO DE PALESTRAS SOBRE AGRICULTURA ORGÂNICA, 2., 1997, São Paulo. Resumos... Campinas: Fundação Cargill, 1997.

ZONTA, E. P.; MACHADO, A. A. Sistema de análise estatística para microcomputadores (SANEST). Pelotas: UFPel, 1991. 101 p. 